\title{
Mental health promotion for the widows of injecting drug users in north-east India
}

\author{
Helen Herrman, ${ }^{1}$ Michelle Kermode, ${ }^{2}$ Alex Devine ${ }^{2}$ and Prabha Chandra ${ }^{3}$
}

\author{
${ }^{1}$ Professor of Psychiatry, Orygen Youth Health Research Centre, Department of Psychiatry, University of Melbourne, \\ Locked Bag 10, Parkville 3052, Victoria, Australia, email h.herrman@unimelb.edu.au; \\ ${ }^{2}$ Nossal Institute for Global Health, University of Melbourne, Australia; ${ }^{3}$ National Institute of Mental Health, Bangalore, India
}

T he prevalence of HIV is high in the north-east Indian states of Manipur and Nagaland. The major route of HIV transmission is injecting drug use. Most injecting drug users (IDUs) are male and about $40 \%$ are married. The widows of IDUs are among the most disadvantaged people. Many are HIV-infected and experiencing poverty, poor health, social isolation and discrimination, all factors likely to compromise their mental health. Some widows are engaging in HIV risk behaviours, including alcohol and drug misuse, sex work and unprotected sex. There is increasing recognition of the links between poverty and mental health status and risk of HIV infection. People with poor mental health are more likely to engage in HIV risk behaviours.

Mental health can be promoted by public health actions with vulnerable population groups. The World Health Organization (WHO) has recently published reports on mental health promotion and women's mental health $(\mathrm{WHO}$, 2000; Herrman et al, 2005) and these have highlighted the emerging evidence base for effective public health actions, as well as the need for practical collaboration between health and non-health sectors. Mental health is more than simply the absence of mental illness; it is the foundation for the well-being and effective functioning of individuals and communities (WHO, 2007). Mental illness is associated with indicators of poverty, including low levels of education, poor housing and low income, and with a range of illnesses, including HIV infection (Freeman et al, 2005). HIV infection and depression, as well as other health and social problems such as substance misuse and violence, are more prevalent and more difficult to cope with in conditions of low income, limited education and unemployment (Desjarlais et al, 1995).

A public health framework adopted by the WHO and proposed initially by the Victorian Health Promotion Foundation (Walker et al, 2005) identifies three key social and economic determinants of community and individual mental health: (1) social inclusion; (2) freedom from discrimination and violence; and (3) access to economic resources. This framework recognises that psychosocial and economic factors influence a number of health-related behaviours, such as substance misuse and risky sexual behaviours (Chandra et al, 2003).

Although the health benefits of community participation are well understood in development work, health policy does not always reflect this, partly because the published evidence related to this approach is limited. Our intervention drew on participatory action research (PAR) approaches to health development. Researchers work with specific communities to identify problems and develop solutions. This enhances self-confidence and leadership skills, and helps members of the community to address their own health and social needs. For example, a study in Nepal demonstrated that communitybased participatory action had a significant positive impact on maternal and infant mortality (Manandhar et al, 2004).

We aimed to take the first steps to evaluate the use of participatory action groups (PAGs) to promote the mental health of IDU widows, as a strategy for HIV prevention (Devine et al, 2007; Kermode et al, 2008).

\section{Method}

We designed a pilot intervention study to assess the feasibility and impact of PAGs to promote the mental health and well-being of widows of IDUs in Manipur and Nagaland, as a strategy for reducing the risk of engagement in HIV risk behaviours. An intervention over 20 weeks included 74 widows in six peer-facilitated PAGs, with a focus on promoting mental health.

Changes in quality of life, mental health, somatic symptoms and HIV risk behaviours were assessed using questionnaires and rating scales. This paper, though, reports the value of the intervention from the perspective of the participants, captured using a qualitative evaluation method, 'most significant change' (MSC). This method is a qualitative, participatory approach to monitoring and evaluation used in development projects (Davies \& Dart, 2004). We collected 'stories of change' from participants during the eighth PAG meeting, and involved different stakeholders in the systematic selection of those stories that best captured what they considered to be the 'most significant change'. Reasons for selecting particular stories were also documented. The point of MSC is that both the content of the selected stories and the reasons for choosing them make the values of the different stakeholders explicit. This can be used to foster dialogue between potentially competing perspectives, in this case that of the IDU widows and the non-governmental organisations (NGOs). As the MSC approach tends to elicit positive stories (in relation to the intervention), this method is not used as an evaluation tool in isolation.

The study was funded by the UK Department for International Development (DFID) through the Research and Learning Fund. Ethics approval was obtained from the University of Melbourne Human Research Ethics Committee (Australia) and the Emmanuel Hospital Association Institutional Review Board (India) in early 2006. 


\section{Results}

The questionnaire responses indicated that the participants' quality of life, mental health and physical health improved over the course of the intervention. The women told stories about 'significant changes' highlighting the positive impact of the intervention, with themes of economic participation, social inclusion, discrimination, physical health and future orientation. Information about HIV risk behaviours was limited by inhibitions about reporting sexual behaviours.

Each of the groups developed an action plan for promoting mental health and the longer-term sustainability of the group. Several of these plans included proposals for income generation.

A relatively generous allowance was paid to the women to cover travel and childcare costs. No allowance was paid to the women after the PAGs concluded, but support for continuing meetings was given by NGOs. Although we do not know the extent to which the allowance influenced participation, this was important in motivating and recruiting women to participate in the intervention at the outset. Six months after the last PAG meeting, five of the six groups were still meeting and some have since expanded their activities.

\section{Discussion}

This participatory intervention study to promote the mental health of widows of IDUs apparently had a positive impact on the participants' quality of life and mental health. However, the sustainability of the improvement and the links between this and their engagement in HIV risk behaviours remain to be demonstrated. The intervention also increased awareness among the NGO leadership of the situation faced by the widows of IDUs. The MSC process was important in this.

Widows in India are socially and economically disadvantaged, and the situation for widows of IDUs is often worse. They are frequently stigmatised on three levels - for being a woman, for being a widow and for being HIV-positive.
Participatory approaches to mental health promotion may well have a positive impact on the lives of vulnerable women and potential to contribute to HIV prevention. Poverty alleviation through economic participation is likely to be a mediating factor, as well as a consequence of improved mental health. Further investigation is warranted.

\section{References}

Chandra, P. S., Carey, M. P., Carey, K. B., et al (2003) HIV risk behaviour among psychiatric inpatients: results from a hospital-wide screening study in southern India. International Journal of STD and AIDS, 14, 532-538.

Davies, R. \& Dart, J. (2004) The Most Significant Change (MSC) Technique: A Guide To Its Use. Available at http://www.mande.co.uk/ docs/MSCGuide.htm (accessed May 2009).

Desjarlais, R., Eisenberg, L., Good, B., et al (1995) World Mental Health: Problems and Priorities in Low-Income Countries. Oxford University Press.

Devine, A., Kermode, M., Chandra, P., et al (2007) A participatory intervention to improve the mental health of widows of injecting drug users in north-east India as a strategy for HIV prevention. BMC International Health and Human Rights, 7, 3.

Freeman, M., Patel, V., Collins, P., et al (2005) Integrating mental health in global initiatives for HIV/AIDS. British Journal of Psychiatry, 187, 1-3.

Herrman, H., Saxena, S. \& Moodie, R. (eds) (2005) Promoting Mental Health: Concepts, Emerging Evidence, Practice. World Health Organization.

Kermode, M., Devine, A., Chandra, P., et al (2008) Some peace of mind: assessing a pilot intervention to promote mental health among widows of injecting drug users in north-east India. BMC Public Health, 8, 294.

Manandhar, D. S., Osrin, D., Shrestha, B. P., et al (2004) Effect of a participatory intervention with women's groups on birth outcomes in Nepal: cluster-randomised controlled trial. Lancet, 364, 970-979.

Walker, L., Verins, I., Moodie, R., et al (2005) Responding to the social and economic determinants of mental health: a conceptual framework for action. In Promoting Mental Health: Concepts, Emerging Evidence, Practice (eds H. Herrman, S. Saxena \& R. Moodie). World Health Organization.

WHO (2000) Women's Mental Health: An Evidence Based Review. World Health Organization.

WHO (2007) Mental Health: Strengthening Mental Health Promotion. Fact Sheet 220. World Health Organization.

\section{College at the TOP conference}

The TOP (Teachers of Psychiatry) conference in Singapore (24-25 February 2009) was organised by the Department of Psychological Medicine, National University of Singapore, with the participation of the Western Pacific Division of the Royal College of Psychiatrists, Pacific Rim College of Psychiatrists and Asian Federation of Psychiatric Associations. There were 270 participants, from Asia, Australia, the USA and Europe. The College provided financial assistance to 16 young psychiatrists from Asia.

The keynote lecture, 'Training psychiatrists for the future', was delivered by Professor Norman Sartorius. The College
President, Professor Dinesh Bhugra, spoke on training the trainers, Emeritus Professor Scott Henderson gave tips on teaching research skills and Professor M. P. Deva discussed issues of primary care psychiatry in Asia.

The conference stirred renewed interest in psychiatric education and academic psychiatry. The participants indicated that the most stimulating and relevant topics discussed were: o training the trainers

o psychiatric education for primary care doctors

O campus mental health

$O$ rethinking psychological therapy in Asia.

The TOP club intends to organise future workshops in Asia on these four topics. 